\title{
Referring patients to nurses: Outcomes and evaluation of a nurse flexible sigmoidoscopy training program for colorectal cancer screening
}

\author{
Mark J Dobrow $\mathrm{PhD}^{1,7}$, Mary Anne Cooper MD MSc MEd ${ }^{2,3}$, Karen Gayman $\mathrm{RN} \mathrm{BScN}^{4}$, Jason Pennington $\mathrm{MD}^{5}$, \\ Joanne Matthews RN CPN $(C)^{6}$, Linda Rabeneck MD MPH ${ }^{2,7,8}$
}

\begin{abstract}
MJ Dobrow, MA Cooper, K Gayman, J Pennington, J Matthews, L Rabeneck. Referring patients to nurses: Outcomes and evaluation of a nurse flexible sigmoidoscopy training program for colorectal cancer screening. Can J Gastroenterol 2007;21(5):301-308.
\end{abstract}

Colorectal cancer is a significant health burden. Several screening options exist that can detect colorectal cancer at an early stage, leading to a more favourable prognosis. However, despite years of knowledge on best practice, screening rates are still very low in Canada, particularly in Ontario. The present paper reports on efforts to increase the flexible sigmoidoscopy screening capacity in Ontario by training nurses to perform this traditionally physicianperformed procedure. Drawing on American, British and local experience, a professional regulatory framework was established, and training curriculum and assessment criteria were developed. Training was initiated at Princess Margaret Hospital and Sunnybrook and Women's College Health Sciences Centre in Toronto, Ontario. (During the study, Sunnybrook and Women's College Health Sciences Centre was deamalgamated into two separate hospitals: Women's College Hospital and Sunnybrook Health Sciences Centre.) Six registered nurses participated in didactic, simulator and practical training. These nurses performed a total of 77 procedures in patients, 23 of whom had polyps detected and biopsied. Eight patients were advised to undergo colonoscopy because they had one or more neoplastic polyps. To date, six of these eight patients have undergone colonoscopy, one patient has moved out of the province and another patient is awaiting the procedure. Classifying the six patients according to the most advanced polyp histology, one patient had a negative colonoscopy (no polyps found), one patient's polyps were hyperplastic, one had a tubular adenoma, two had advanced neoplasia (tubulovillous adenomas) and one had adenocarcinoma. All these lesions were excised completely at colonoscopy. Overall, many difficulties were anticipated and addressed in the development of the training program; ultimately, the project was affected most directly by challenges in encouraging family physicians to refer patients to the program. As health human resource strategies continue to evolve, it is believed that lessons learned from experience make an important contribution to the knowledge of how nontraditional health services can be organized and delivered.

Key Words: Colorectal cancer screening; Flexible sigmoidoscopy; Health human resource strategy; Nonphysician endoscopy

\begin{abstract}
Aiguillage de patients vers du personnel infirmier : résultats et évaluation d'un programme infirmier de formation en sigmoïdoscopie souple pour le dépistage du cancer colorectal
\end{abstract}

Le cancer colorectal impose un lourd tribut au système de santé. Plusieur méthodes de dépistage permettent de détecter le cancer colorectal à un stade précoce, ce qui en améliore le pronostic. Cependant, malgré les connaissances accumulées depuis des années sur la démarche, les taux de dépistage de la maladie sont encore très faibles au Canada, surtout en Ontario. Le présent article fait état d'un effort particulier visant à accroître le nombre d'examens de dépistage du cancer colorectal par sigmoïdoscopie souple en Ontario par la formation de personnel infirmier dans un acte traditionnellement réservé aux médecins. Un cadre réglementaire professionnel a été établi à partir des expériences menées aux États-Unis, en Grande-Bretagne et au niveau local; nous avons ensuite élaboré un programme de formation et des critères d'évaluation. Le programme a été mis en œuvre au Princess Margaret Hospital et au Sunnybrook and Women's College Health Sciences Centre, à Toronto (pendant l'étude, le centre médical Sunnybrook and Women's a été divisé en deux hôpitaux : le Women's College Hospital et le Sunnybrook Health Sciences Centre). Six infirmières autorisées ont participé à la formation théorique et pratique ainsi qu'aux exercices de simulation. Ces infirmières ont pratiqué en tout 77 examens, et des polypes ont été détectés et biopsiés chez 23 patients. On a conseillé à huit d'entre eux de subir une coloscopie parce qu'ils étaient porteurs d'au moins un polype néoplasique. Sur les huit patients, six ont déjà passé la coloscopie, un a quitté la province et un autre est dans l'attente de l'examen. Voici les résultats par ordre croissant de classification histologique : coloscopie négative (absence de polypes détectés) (1), polype hyperplasique (1), adénome tubuleux (1), néoplasie évoluée (adénome tubulovilleux) (2) et adénocarcinome (1). Tous les polypes en question ont été extirpés au moment de la coloscopie. Dans l'ensemble, bon nombre de problèmes ont été prévus et résolus dans l'élaboration du programme de formation; ce sont finalement les efforts visant à inciter les médecins de famille à diriger leurs patients vers du personnel infirmier qui ont le plus directement modifié le projet. Comme les stratégies d'utilisation des ressources humaines en santé ne cessent d'évoluer, nous sommes d'avis que les leçons tirées de l'expérience permettront d'en apprendre beaucoup sur l'organisation et la prestation de services de santé non traditionnels.

\footnotetext{
${ }^{1}$ Department of Health Policy, Management and Evaluation, University of Toronto; ${ }^{2}$ Division of Gastroenterology, University of Toronto;

${ }^{3}$ Sunnybrook Health Sciences Centre; ${ }^{4}$ Princess Margaret Hospital, University Health Network; ${ }^{5}$ Toronto Western Hospital,

University Health Network; ${ }^{6}$ Women's College Hospital; ${ }^{7}$ Cancer Care Ontario; ${ }^{8}$ Institute for Clinical Evaluative Sciences, Toronto, Ontario Correspondence: Dr Mark J Dobrow, Cancer Care Ontario, 620 University Avenue, Toronto, Ontario M5G 2L7.

Telephone 416-217-1380, fax 416-971-6888, e-mail mark.dobrow@cancercare.on.ca

Received for publication October 22, 2006. Accepted February 13, 2007
} 
$\mathrm{T}_{\mathrm{s}}^{\mathrm{h}}$ he incidence of and mortality from colorectal cancer in Canada is among the highest in the world $(1,2)$. In Ontario, colorectal cancer is the most common cause of cancer-related death among nonsmokers; the lifetime risk of developing colorectal cancer is approximately one in $14(3,4)$. In 2006, it was estimated that approximately 7500 Ontario residents would be diagnosed with colorectal cancer and approximately 3100 would die of the disease (4).

Screening the average-risk population (eg, those 50 years of age and older, are asymptomatic and have no family history) for colorectal cancer is critical. For the purposes of the present paper, our definition of colorectal cancer screening tests includes both tests that have the capacity to detect colorectal cancer earlier in its progression, such as the fecal occult blood test (FOBT), and tests that can detect precursors to cancer (eg, polyps), such as flexible sigmoidoscopy and colonoscopy. Colorectal cancer screening tests detect cancers at an early stage, resulting in a better prognosis than in those in whom cancer is detected due to symptom development (5). However, despite the availability of colorectal cancer screening tests for over 20 years and screening recommendations from numerous national and international expert bodies (2,6-11), less than $20 \%$ of the eligible population in Ontario has been screened for colorectal cancer (1). The implications are that by not adhering to these recommendations, more people are dying from the disease than otherwise would be.

Colorectal cancer screening is somewhat unusual in that there are a number of different screening tests, each with strengths and weaknesses, and none clearly dominating in population-based organized screening programs. Currently, the FOBT is the only screening option supported by strong experimental evidence (12-15). The test is relatively inexpensive, allowing significant numbers of the screen-eligible population to be screened. However, the main limitation with the FOBT is that it produces false-positive results that have important downstream resource implications (16).

Endoscopic screening options include colonoscopy and flexible sigmoidoscopy. Colonoscopy is considered the gold standard for detecting colorectal cancer and polyps because it allows visualization of the entire colon, the most complete polyp detection and immediate polyp removal. When another screening test produces a positive result, a colonoscopy is the required follow-up procedure. However, colonoscopy is not currently endorsed in Canada as an initial screening test in average-risk individuals (8). In addition, from a populationbased perspective, colonoscopy is somewhat onerous in terms of patient preparation and is associated with a risk of serious complications (eg, bowel perforation) $(11,17)$. Flexible sigmoidoscopy has characteristics that are more suitable for populationbased screening. Although flexible sigmoidoscopy does not visualize the entire colon as does colonoscopy, it has a less onerous patient preparation requirement, does not require conscious sedation and is safer to use (eg, lower bowel perforation rate for flexible sigmoidoscopy than colonoscopy) (18). Preliminary results from a United Kingdom (UK)-based randomized controlled trial of flexible sigmoidoscopy screening indicated that test performance characteristics are likely to be at least equivalent to FOBT screening (19). Furthermore, economic evaluations on colorectal cancer screening consistently suggest that flexible sigmoidoscopy is a cost-effective screening modality (20-22).
While the debate continues, a wide range of evidentiary sources strongly suggest that screening with any of these tests will reduce mortality rates associated with colorectal cancer, and this will prolong lives. Cancer Care Ontario and the Ontario Ministry of Health and Long-Term Care are working together to develop an organized FOBT screening program to ensure that the greatest number of Ontarians are screened. There is also an interest in developing a complementary flexible sigmoidoscopy screening program. However, Ontario, like most jurisdictions, faces serious capacity issues to deliver endoscopic services both for screening and follow-up (18). In Ontario, flexible sigmoidoscopy is provided mainly by general surgeons (45\%) and gastroenterologists (38\%), with less than $5 \%$ provided by primary care physicians (18). Between 1992 and 2001, the total number of flexible sigmoidoscopy procedures provided in Ontario actually dropped by $12 \%$ (18). Colonoscopy rates have increased sharply in Ontario over the same time period, offsetting this decline in flexible sigmoidoscopy (18). However, current colonoscopy capacity is insufficient to meet increased demand for follow-up of positive FOBT or flexible sigmoidoscopy screens that would result from organized screening, and far below the capacity needed if colonoscopy was to be used as a primary screening test. Therefore, flexible sigmoidoscopy still represents a key endoscopic primary screening option.

Since the 1970s (23), several jurisdictions around the world have employed nonphysicians to provide flexible sigmoidoscopies (24). Studies consistently show no clinically significant differences between gastroenterologists or general surgeons and nurses or other appropriately trained nonphysician endoscopists in terms of polyp-miss or complication rates (25-31). Studies also suggest that nonphysician endoscopists may be more cost-effective $(28,31)$ and do not impact negatively on patient satisfaction $(30,32)$. While the randomized controlled Multi-Institution Nurse Endoscopy Trial (MINuET) in the UK recently provided more definitive evidence of the acceptability, effectiveness, cost and outcomes of flexible sigmoidoscopy performed by nurses compared with physicians (33), the evidence available before the initiation of the project supported nonphysician-performed sigmoidoscopy as a safe, effective approach to increase flexible sigmoidoscopy capacity for polyp detection and reduce colorectal cancer mortality.

It was on this basis that a nurse flexible sigmoidoscopy training program was launched in Ontario. The present paper describes the development and evaluation of this program.

\section{DEVELOPMENT OF THE NURSE FLEXIBLE SIGMOIDOSCOPY TRAINING PROGRAM}

International evidence (27,34-38) and local experience $(31,39)$ strongly suggest that nonphysician endoscopy is not limited by doubts of safety or efficacy, but rather is constrained by professional regulatory, funding, service delivery and organizational issues. Through a Change Foundation grant, these issues became the central focus in our efforts to develop a nurse flexible sigmoidoscopy training program.

\section{Regulatory framework}

The first key challenge was to determine whether the scope of practice for registered nurses (RNs) in Ontario enabled them to perform the flexible sigmoidoscopy procedure. The Cancer Quality Council of Ontario established the Ontario Task Force on Large Bowel Endoscopic Services, which represented a wide 
range of experts and stakeholders, to address critical regulatory issues, including performance of controlled acts, the role of medical directives, requirements for physician availability or support, and communicating assessment of findings. Ultimately, the Task Force determined that the Ontario Regulated Health Professions Act and the Nursing Act allowed the performance of flexible sigmoidoscopy with biopsy by RNs (general class), for the purpose of assessment, to be within their scope of practice (40). This was an important advancement from an earlier attempt to establish flexible sigmoidoscopy in Ontario, where nurses were not authorized to perform biopsies (31). However, the regulatory framework still required a medical directive, an on-site physician for clinical backup support and decision-making when necessary, and pathology reports to be directed to that physician. Communication of procedure findings were to be delivered through the development of standardized letters and not directly by nurses.

\section{Professional liability protection and remuneration}

Nurses' professional liability protection was included as part of typical hospital employee coverage, through the Healthcare Insurance Reciprocal of Canada, with additional occurrencebased liability protection provided by the Canadian Nurses Protective Society for nurses who were members of the Registered Nurses Association of Ontario. The Canadian Medical Protective Association provided special professional liability protection for physician trainers that was specific to this training program (liability protection for physicians posttraining or in an expanded training program needed to be addressed).

The study hospitals agreed to cover the prorated salary costs of trainees and endoscopy support staff for time allocated to the training program. Each physician trainer received a stipend to cover some of his or her lost billable time due to participation in the training program. Other remuneration issues needed to be addressed for the post-training context, in which physicians would not directly observe nurse-performed procedures, but provide on-site backup and follow-up with pathology reports, and be responsible for communicating findings to patients.

\section{Training curriculum and assessment criteria}

Drawing on established training programs in the United States and the UK, a curriculum was developed. It consisted of a didactic component reviewing the relevant anatomy, physiology and pathology of the gastrointestinal tract; flexible sigmoidoscopy training on a computer simulator; and practical training on patients recruited for the study. Assessment criteria for each component of training included knowledge tests, assessment of technical performance (checklists and global rating scales were developed to monitor the trainees' progress, including depth of insertion, duration of procedure, number and characteristics of polyps detected or removed, and rates of complications or adverse events) for both simulator and practical procedures, and patient satisfaction questionnaires.

A key objective of the project was to examine the number of procedures required for nurses to attain competence across the range of specified assessment criteria in performing flexible sigmoidoscopy independently, safely and effectively. Other existing training programs provided inconsistent guidance for the number of procedures required, ranging from performing
TABLE 1 Training schedule and patients required

\begin{tabular}{|c|c|c|c|}
\hline $\begin{array}{l}\text { Session } \\
\text { number }\end{array}$ & Training component & $\begin{array}{c}\text { Days } \\
(n=16) \\
n\end{array}$ & $\begin{array}{l}\text { Patients required } \\
\text { at both sites } \\
(n=396) \\
n\end{array}$ \\
\hline 1 to 2 & Didactic training & 2 & $\mathrm{~N} / \mathrm{A}$ \\
\hline 3 & Simulator training & 1 & $N / A$ \\
\hline 4 & $\begin{array}{l}\text { Observation of physician } \\
\text { trainer-performed procedures }\end{array}$ & 0.5 & 12 \\
\hline 4 & $\begin{array}{l}\text { Practical training on patients } \\
\text { (two per trainee per half-day) }\end{array}$ & 0.5 & 12 \\
\hline 5 & Workshop with international experts & 1 & $\mathrm{~N} / \mathrm{A}$ \\
\hline 6 to 11 & $\begin{array}{l}\text { Practical training on patients } \\
\text { (five per trainee per day) }\end{array}$ & 6 & 180 \\
\hline 12 to 15 & $\begin{array}{l}\text { Practical training on patients } \\
\text { (eight per trainee per day) }\end{array}$ & 4 & 192 \\
\hline 16 & $\begin{array}{l}\text { Debriefing session for trainees } \\
\text { and trainers }\end{array}$ & 1 & $N / A$ \\
\hline
\end{tabular}

N/A Not applicable

25 to over 100 procedures $(27,35,36,41,42)$. Therefore, the program was set up to begin on March 3, 2006, and run over 16 of 18 Fridays until June 30, 2006 (exceptions were during March break and Good Friday). This schedule required a total of 396 procedures in patients, with 12 procedures allocated to physician trainers and 64 procedures allocated to each trainee (Table 1).

\section{Equipment and space requirements}

The two study hospitals provided clinic space for the training program, which included two procedure rooms to be run simultaneously and waiting room space. Both study sites required additional flexible sigmoidoscopes and associated equipment, including light source units, processors and image capturers. Disposable equipment necessary for procedures (ie, biopsy forceps) were also required, in addition to routine medical supplies such as biopsy sample bottles, formalin solution, saline, etc. Existing endoscope reprocessing equipment was used at both sites.

\section{Recruitment of physician trainers, nurse trainees and endoscopy support staff}

In addition to the equipment and space requirements, each study site was to recruit three RNs to participate in the training program, two endoscopy nurses (one per procedure room) to assist during the procedure (standard practice for physicianperformed flexible sigmoidoscopy), and one endoscope reprocessing technician to ensure timely cleaning and preparation of the sigmoidoscopes during the procedure sessions. A gastroenterologist and a surgeon, members of the project team, took on the role of physician trainers, one at each site.

The training program was not designed to require full-time participation of trainees, nor was the intent that nurses would take on flexible sigmoidoscopy full-time post-training. The optimum proportion of time devoted to flexible sigmoidoscopy has not been established. For this training program, trainees, trainers and endoscopy support staff were engaged in their usual practice every day except the Fridays devoted to the course. 
TABLE 2

Referral distribution $(n=178)$

\begin{tabular}{lcc}
\hline Referral status & $\begin{array}{c}\text { Referrals, } \\
\mathbf{n}\end{array}$ & $\%$ \\
\hline $\begin{array}{l}\text { Referrals completing procedure (excludes } \\
\text { four patients who received a second procedure }\end{array}$ & 77 & 43 \\
due to poor preparation) & & \\
\hline Referrals not meeting eligibility criteria & 13 & - \\
Referrals declining to participate & 19 & - \\
Total & 32 & 18 \\
\hline Referrals consenting to participate (excludes & 6 & - \\
$\quad$ one patient awaiting scheduling for a & & \\
$\quad$ second procedure due to poor preparation) & 5 & - \\
Referrals waiting to schedule a consent appointment & 5 & 6 \\
$\quad$ Total & 11 & 12 \\
\hline Referrals contacted but uncertain about participating & 22 & - \\
\hline Referrals contacted indirectly (eg, messages left) & 18 & - \\
Referrals yet to be contacted & 18 & 20 \\
\hline Total & 36 & \\
\hline
\end{tabular}

\section{Patient recruitment}

To ensure proper patient follow-up and facilitate referrals to follow-up colonoscopy, if required, patients could only be referred to the nurse flexible sigmoidoscopy training program through a family physician. Because no established mechanism for referring patients to nurses existed, a centralized patient booking system was set up at Cancer Care Ontario. A single fax number was designated to which all referrals from family physicians were sent. Family physicians, from a number of local private and hospital-based practices, were informed of the project through 'lunch and learn' education sessions conducted by a gastroenterologist. These physicians were provided with posters, brochures and referral forms that included a checklist for patient eligibility criteria.

The Princess Margaret Hospital Foundation (Toronto, Ontario) also informed its donors of the program through a newsletter and, similarly, posters describing the project were posted at the study site hospitals and two other teaching hospitals affiliated with the University of Toronto (Toronto, Ontario), instructing those interested to consult with their family physician, who could refer them for screening. The project's modest budget did not allow advertising through traditional media and, given the limited scale of the project, which operated at only two sites in downtown Toronto, it was not considered an effective or efficient method to increase awareness for patients and/or family physicians in our target area.

Because the training program included an evaluation component, ethics approval required that study consent be obtained from all patient participants, in addition to procedure consent that was still required of all patients and obtained by the nurse trainees at the time of the clinical encounter at the hospital. While the study consent requirement would not be part of a normal nurse flexible sigmoidoscopy operation, it was necessary that a study consent process be merged with the patient booking system. A study consent coordinator contacted all patients referred for a flexible sigmoidoscopy and assessed their eligibility for the study over the telephone. Patients who met basic eligibility criteria were invited to attend an office appointment at Cancer Care Ontario, at which time all aspects of the study were reviewed with the patient. Written consent for study participation was obtained at this time, and willing patients were assigned to have their procedure performed at one of the two study hospitals. Each patient was provided with a package that included directions to the designated hospital and procedure preparation instructions (eg, enema).

\section{OUTCOMES AND EVALUATION: REFERRING PATIENTS TO NURSES}

Multiple methods were used to evaluate the program, including key informant interviews, focus groups, procedural performance data and feedback, patient satisfaction surveys and international expert reviews.

The regulatory framework, liability and remuneration issues were all addressed satisfactorily, and equipment and space were deemed to be adequate for the purposes of the program. Few difficulties were encountered in recruiting trainees. In posttraining focus groups, the trainees were enthusiastic about the opportunity to develop new skills and take on a new specialized role that would contribute to colorectal cancer screening efforts. Our experience suggests that the opportunity for nurses to obtain flexible sigmoidoscopy training enhances recruitment and retention efforts. The project also generated interest among physicians across Ontario who could potentially participate in the training program if expanded.

Over the course of the project, 178 patients were referred to the training program for flexible sigmoidoscopy screening. As of June 30, 2006, of these 178 referrals, 77 (43\%) had completed the procedure, $32(18 \%)$ were ineligible or declined to participate, $11(6 \%)$ were waiting for either a consent or procedure appointment, 22 (12\%) were uncertain and had yet to agree to participate, and 36 (20\%) still required direct contact (Table 2). While most of the project components were implemented or addressed successfully, the training program was clearly dominated by problems with patient recruitment. This was evident by the fact that the 178 patients referred were far below the 396 patients needed to fulfill the course objectives.

Of those patients who declined to participate, only two expressed concern about a nurse performing the procedure. Other reasons for declining to participate included preferring colonoscopy over flexible sigmoidoscopy, unavailability during given time slots, preferring care closer to home, preferring to be sedated during the procedure (not an option in the study) and lack of awareness that the screening test was part of a study.

Poor bowel preparation resulted in five patients being referred for a repeat flexible sigmoidoscopy, of which four were completed as of June 30, 2006. (One of these patients also had poor bowel preparation for the second flexible sigmoidoscopy and, therefore, was referred for colonoscopy, which was negative.) Thus, 81 flexible sigmoidoscopies were completed in 77 patients as of June 30,2006 . The number performed by individual trainees ranged from three to 18 (Table 3 ).

Polyps were detected and biopsied in 23 patients. Of these 23 patients, 15 patients had hyperplastic polyps and were advised to undergo another flexible sigmoidoscopy procedure in five years. The remaining eight patients' polyps showed neoplastic change, and were advised to undergo a colonoscopy. To date, six of these eight patients have undergone colonoscopy, one patient has moved out of the province and 
TABLE 3

Number of procedures performed by trainee or trainer

\begin{tabular}{lc}
\hline Trainee or trainer & $\begin{array}{c}\text { Number of procedures performed } \\
(\mathbf{n = 8 1 )}\end{array}$ \\
\hline Nurse & \\
A & 13 \\
B & 14 \\
C & 18 \\
D & 14 \\
E & 15 \\
F $^{*}$ & 3 \\
Physician trainers (demonstration procedures) & 4
\end{tabular}

*Nurse $F$ suffered a hand injury (unrelated to the program) at the outset of training which delayed the initiation of patient training

another patient is awaiting the procedure. Patients were classified on the basis of their most advanced polyp histology: no polyp, hyperplastic polyp, tubular adenoma or advanced neoplasm. Of the six patients undergoing colonoscopy, one had a negative colonoscopy (no polyps found), one patient's polyps were hyperplastic, one had a tubular adenoma, two had advanced neoplasia (tubulovillous adenomas) and one had adenocarcinoma. All these lesions were excised completely at colonoscopy.

With an average of fewer than 12 referrals made to the central booking office per week, the planned procedure schedule could not be maintained. Therefore, the decision was made to run an extra day of simulator training, reduce most sessions to half-days and cancel three sessions completely. As the project progressed, it was clear that the volume of referrals would only allow running of a half-day session every other week. This inconsistency did not provide the trainees with sufficient opportunities to advance their skill level, and given clinical and personal commitments of the physician trainers, the decision was made to suspend the course until referrals were accumulated so that full-day sessions could be run on consecutive weeks.

\section{Factors affecting referrals}

Patient recruitment was clearly the greatest challenge for the program; however, factors that had the greatest impact on the family physician's decision to refer patients to the program were uncertain. While the project was not designed to study patient recruitment directly, the experience provided a number of insights on family physicians' referrals of patients to nurses for flexible sigmoidoscopy.

Awareness of the screening program was clearly important. Because patients needed to be referred by family physicians, the project did not focus on direct-to-patient recruitment strategies. Some efforts to reach potential patients directly were made (eg, through the Princess Margaret Hospital Foundation newsletter and posters at the study sites), which resulted in a small number of inquiries. The added step requiring patients to consult with their family physician, who might or might not have been aware of the nurse flexible sigmoidoscopy program, might have reduced referrals. Because patients might have had to wait to schedule nonurgent appointments with their family physician, there might have been a time lag that was not detected as of the suspension date for the program. Direct-to-patient recruitment might have been bolstered by mass media advertising; however, because
TABLE 4

Referrals by family physician

\begin{tabular}{|c|c|c|}
\hline Family physician & $\begin{array}{c}\text { Referrals, } \\
\text { n (\%) }\end{array}$ & $\begin{array}{c}\text { Cumulative, } \\
(\%)\end{array}$ \\
\hline A (from two practice locations) & $61(34)$ & 34 \\
\hline B (from six practice locations) & $24(13)$ & 48 \\
\hline C & $17(10)$ & 57 \\
\hline D (from three practice locations) & $14(8)$ & 65 \\
\hline $\mathrm{E}$ & $14(8)$ & 73 \\
\hline $\mathrm{F}$ & $13(7)$ & 80 \\
\hline G & $5(3)$ & 83 \\
\hline $\mathrm{H}$ & $5(3)$ & 86 \\
\hline । & $3(2)$ & 88 \\
\hline Two family physicians with two referrals & $4(2)$ & 90 \\
\hline 18 family physicians with one referral & $18(10)$ & 100 \\
\hline Total referrals from 29 family physicians & $178(100)$ & - \\
\hline
\end{tabular}

TABLE 5

Referrals by family physician practice location

\begin{tabular}{lcc}
\hline Practice location & $\begin{array}{c}\text { Referrals, } \\
\mathbf{n}(\%)\end{array}$ & $\begin{array}{c}\text { Cumulative, } \\
\text { (\%) }\end{array}$ \\
\hline A (six different family physicians) & $73(41)$ & 41 \\
B (two different family physicians) & $22(12)$ & 53 \\
C (two different family physicians) & $20(11)$ & 65 \\
D & $17(10)$ & 74 \\
E & $6(3)$ & 78 \\
F & $6(3)$ & 81 \\
G & $4(2)$ & 83 \\
H & $4(2)$ & 85 \\
I & $3(2)$ & 87 \\
Three locations with two referrals & $6(3)$ & 90 \\
$\quad$ four different family physicians) & & \\
17 locations with one referral & $17(10)$ & 100 \\
Total referrals from 29 practice locations & $178(100)$ & - \\
\hline
\end{tabular}

the program was not positioned to meet broad-based demand, this strategy could not be implemented. Until nurse flexible sigmoidoscopy becomes established in Ontario, there are limits on the extent of broad-based advertising usage, but it may be a critical component in creating sufficient demand to evaluate the potential of nurse flexible sigmoidoscopy screening.

The primary strategy for increasing awareness of the program was a direct-to-family physician approach, primarily through lunch and learn sessions. These sessions provided an opportunity to set out the arguments for nurse flexible sigmoidoscopy screening to the primary target audience. It was unclear what impact these direct-to-family physician efforts had on referrals. Six family physicians accounted for $80 \%$ of all referrals (Table 4), while only four practice locations produced referrals from more than one family physician (Table 5). While a few family physicians clearly embraced the nurse flexible sigmoidoscopy program, their activities often did not translate into greater numbers of referrals from colleagues in their practices. Given that the lunch and learn sessions are resource intensive, we need to be confident that employing experts to discuss and explain the case for nurse-flexible sigmoidoscopy was a cost-effective method for increasing referrals. 
An important benefit of conducting the lunch and learn sessions was the opportunity to discuss directly with family physicians the factors influencing their decision to refer. The clarity of the colorectal cancer screening message was often cited as a problem. Family physicians indicated that many 'messages' conflicted with the project's flexible sigmoidoscopy focus. These included plans to launch an organized provincial FOBT screening program, the emergence of the fecal immunochemical test as a potential replacement for guaiac-based FOBT screening and the perceived superiority of colonoscopy over flexible sigmoidoscopy screening. Given the evolving evidence base for colorectal cancer screening, these mixed messages present an important challenge in assisting family physicians' interpretation of the value of flexible sigmoidoscopy screening for their patients. While new randomized, controlled trial evidence from a UK trial is anticipated in late 2007 or early 2008, which will likely make a stronger case for flexible sigmoidoscopy, it is only presumptive evidence and cannot currently be used to support the nurse flexible sigmoidoscopy program. In light of recommendations from numerous international expert panels supporting flexible sigmoidoscopy and the prevailing low colorectal cancer screening rates in Ontario, family physicians were asked to explain why the majority of their patients were not referred for any colorectal cancer screening test. More specifically, because the nurseflexible sigmoidoscopy program provided a convenient opportunity for family physicians to have their patients screened with only minimal wait times, why did they hesitate to refer patients for flexible sigmoidoscopy if other screening options were not pursued? While clear answers were not apparent, family physicians raised no explicit concerns about the expanding nursing role as a barrier to referring patients for flexible sigmoidoscopy.

Another issue that may have impacted on patient recruitment was the lack of an existing mechanism or infrastructure to refer patients to nurses. In Ontario, family physicians normally refer patients to specialists based on a direct physician-to-physician relationship, with very few centralized referral centres existing. A workshop was held in May 2006 with international experts, which revealed a markedly different referral context for nurse flexible sigmoidoscopy in Ontario than in the National Health Service's nurse endoscopy program in the UK or in Kaiser Permanente's nurse endoscopy program in California, USA. Both of these international exemplars have been operating for many years, and both have benefited from built-in flexible sigmoidoscopy referral pools. In both of these cases, family physicians referred all patients recommended for a flexible sigmoidoscopy to a central referral hub, from which patients could be directed to either a nurse or a physician endoscopist. This consistent pool of referrals, which currently does not exist in Ontario, provided the flexibility to allocate procedures to nurses. While the primary care context in Ontario is evolving, it is clear that the lack of an established mechanism for referring patients to a nurse for a flexible sigmoidoscopy was a constraint on the project's patient recruitment efforts.

The present study was set in a large urban area with an established base of specialists. Consequently, it is uncertain whether the factors affecting patient recruitment would apply if the program was used in different service delivery contexts. Efforts are underway to expand the number and type of sites in Ontario where nurse-flexible sigmoidoscopy training can occur, which will allow examination of other potential models of patient recruitment.

Implications of patient recruitment on program evaluation Patient recruitment difficulties limited our ability to fully evaluate the optimum time to competence. Assumptions made at the outset of the program were based on approximately 60 patients per trainee to ensure that technical competence was achieved. However, because none of the nurses were given the opportunity to perform an adequate number of procedures, none were deemed to have achieved competence when the course was suspended. Both physician trainers indicated that the nurses' skill development was limited only by the lack of patients.

Due to patient recruitment challenges, an additional simulator session was added to the training program. The trainees suggested that this extra session was extremely beneficial. There was further consensus among trainees and trainers that the opportunity to observe more cases before performing the first patient case would provide trainees the opportunity to learn techniques and better understand the interaction between the endoscopist and the endoscopy assistant. The international expert workshop also revealed that trainees in California are given the opportunity to withdraw the sigmoidoscope (after physician insertion) on their initial cadre of patients, which allows their confidence to be built while acquiring technical skills on a less challenging aspect of the procedure. However, with the project's patient recruitment challenges, it was difficult to provide the number of observed and withdraw-only procedures that make existing training programs successful.

The scheduling modifications also had cost implications, with trainees provided their full remuneration throughout the course, despite the reduction in time allotted. Recruitment of endoscopy support staff was also challenging, resulting in week-to-week, last-minute scheduling that did not provide the desired consistency for training.

\section{CONCLUSIONS}

Colorectal cancer is a significant health burden and unrealized opportunities exist in Ontario to increase screening rates. International evidence and experience suggest that nonphysicians can perform flexible sigmoidoscopy safely and effectively. Flexible sigmoidoscopy has been determined to be within the scope of practice for RNs in Ontario. All key training and licensing components have been established. This project demonstrated that nurse-performed flexible sigmoidoscopy is possible in Ontario and can result in the early detection of advanced neoplasia and cancer in patients referred for screening.

However, while international experience informed the development of the curriculum and assessment criteria, it was less relevant to service delivery and organization issues. Context-specific features of the Ontario health system, specifically related to primary care referral, differ significantly from the National Health Service in the UK or a large health maintenance organization in the United States. Overall, the ability to ensure that sufficient numbers of patients were referred for flexible sigmoidoscopy proved to be a critical constraint in establishing nurse flexible sigmoidoscopy as a viable option for increasing colorectal cancer screening rates in Ontario.

After patient recruitment is adequately addressed, it is anticipated that the training program will resume with the 
subsequent establishment of nurse flexible sigmoidoscopy clinics. To achieve this, the next steps include studying and improving the primary care referral mechanism, solidifying the case for flexible sigmoidoscopy as an ideal population-based screening test and examining family physician justification for not referring eligible patients for any screening procedure or test.

ACKNOWLEDGEMENTS: The authors acknowledge and appreciate the contributions of numerous individuals and stakeholder groups, including members of the Ontario Task Force on Large Bowel Endoscopic Services and the Change Foundation grant project team. The Task Force included experts from gastroenterology, surgery, general practice, nursing, organized screening, health practitioner education, health management and policy, and health services research; it also represented a range of key stakeholder organizations. Members included: Dr Linda Rabeneck (Chair) (Sunnybrook Health Sciences Centre, Toronto, Ontario); Dr Sean Blaine (Family Medicine Genetics program, Mount Sinai Hospital, Toronto, Ontario); Heather Campbell (College of Nurses of Ontario); Dr Steve Gallinger (Department of Surgery, Mount Sinai Hospital); Esther Green, Dr Verna Mai and Dr Terry Sullivan
(Cancer Care Ontario); Dr Michael Gould (Ontario Association of Gastroenterology); Doris Grinspun (Registered Nurses Association of Ontario); Dr Des Leddin (Canadian Association of Gastroenterology, Oakville, Ontario); Sue Matthews, (Ontario Ministry of Health and Long-Term Care); Dr Lawrence Paszat (Institute for Clinical Evaluative Sciences, Toronto, Ontario); Dr Mary Preece (Michener Institute for Applied Health Sciences, Toronto, Ontario); Dr Ted Shapero (The Scarborough Hospital, Toronto, Ontario); Dr Julie Smallman (Ontario Ministry of Health and Long-Term Care Physician Services Committee's Delegation and Supervision Working Group); Dr Hartley Stern (Ottawa Regional Cancer Program, Ottawa, Ontario). The Change Foundation grant project team included: Drs Linda Rabeneck (Principal Investigator) and Mary Anne Cooper (Sunnybrook Health Sciences Centre); Dr Robert Bell, Nellie Dovgalev, Karen Gayman and Dr Jason Pennington (University Health Network); Christine Barrett, Nancy Malcolm and Joanne Matthews (Women's College Hospital, Toronto, Ontario); Angela Cuddy and Dr Mary Preece (Michener Institute for Applied Health Sciences); Dr Lawrence Paszat (Institute for Clinical Evaluative Sciences); Heather Campbell (College of Nurses of Ontario); and Helen Angus, Dr Mark Dobrow, Anna Greenberg and Dr Terry Sullivan (Cancer Care Ontario).

\section{REFERENCES}

1. Rabeneck L, Paszat LF. A population-based estimate of the extent of colorectal cancer screening in Ontario. Am J Gastroenterol 2004;99:1141-4.

2. Public Health Agency of Canada. Technical report for the National Committee on Colorectal Cancer Screening.

<http://www.phac-aspc.gc.ca/publicat/ncccs-cndcc/techrep_e.html> (Version current at February 16, 2007).

3. Cancer Care Ontario. Focus on colorectal cancer in Ontario. $<$ http://www.cancercare.on.ca/documents/ClinicalFocusColorectal.pdf $>$ (Version current at February 16, 2007).

4. Canadian Cancer Society, National Cancer Institute of Canada, Statistics Canada, Provincial/Territorial Cancer Registries, Public Health Agency of Canada. Canadian cancer statistics 2006. <http://www.cancer.ca/vgn/images/portal/cit_86751114/31 /21/935505792cw_2006stats_en.pdf.pdf > (Version current at February 16, 2007).

5. Schoen RE. The case for population-based screening for colorectal cancer. Nat Rev Cancer 2002;2:65-70.

6. Ontario Expert Panel on Colorectal Cancer Screening. Colorectal Cancer Screening: Final Report of the Ontario Expert Panel. Toronto: Cancer Care Ontario, 1999.

7. Leddin D, Hunt R, Champion M, et al; Canadian Association of Gastroenterology; Canadian Digestive Health Foundation. Canadian Association of Gastroenterology and the Canadian Digestive Health Foundation: Guidelines on colon cancer screening. Can J Gastroenterol 2004;18:93-9.

8. Canadian Task Force on Preventive Health Care. Colorectal cancer screening. Recommendation statement from the Canadian Task Force on Preventive Health Care. CMAJ 2001;165:206-8.

9. Australian Health Technology Advisory Committee. Colorectal Cancer Screening. Canberra: Government publishing service, Australia, 1997.

10. Agency for Healthcare Research and Quality. Screening for colorectal cancer: Recommendations and rationale. <http://www.ahrq.gov/clinic/3rduspstf/colorectal/colorr.htm> (Version current at February 16, 2007).

11. Winawer S, Fletcher R, Rex D, et al; Gastrointestinal Consortium Panel. Colorectal cancer screening and surveillance: Clinical guidelines and rationale - Update based on new evidence. Gastroenterology 2003;124:544-60.

12. Mandel JS, Bond JH, Church TR, et al. Reducing mortality from colorectal cancer by screening for fecal occult blood. Minnesota Colon Cancer Control Study. N Engl J Med 1993;328:1365-71. (Erratum in 1993;329:672).

13. Kewenter J, Brevinge H, Engaras B, Haglind E, Ahren C. Results of screening, rescreening, and follow-up in a prospective randomized study for detection of colorectal cancer by fecal occult blood

testing. Results for 68,308 subjects. Scand J Gastroenterol 1994;29:468-73.

14. Kronborg O, Fenger C, Olsen J, Jorgensen OD, Sondergaard O. Randomised study of screening for colorectal cancer with faecal-occult-blood test. Lancet 1996;348:1467-71.

15. Hardcastle JD, Chamberlain JO, Robinson MH, et al. Randomised controlled trial of faecal-occult-blood screening for colorectal cancer. Lancet 1996;348:1472-7.

16. Towler B, Irwig L, Glasziou P, Kewenter J, Weller D, Silagy C. A systematic review of the effects of screening for colorectal cancer using the faecal occult blood test, hemoccult. BMJ 1998;317:559-65.

17. Winawer SJ, Fletcher RH, Miller L, et al. Colorectal cancer screening: Clinical guidelines and rationale. Gastroenterology 1997;112:594-642. (Errata in 1997;112:1060, 1998;114:625).

18. Vinden C, Schultz S, Rabeneck L. ICES research atlas: Use of large bowel procedures in Ontario. <http://www.ices.on.ca/file/ Large_Bowel_R_Atlas.pdf> (Version current at February 16, 2007).

19. UK Flexible Sigmoidoscopy Screening Trial Investigators. Single flexible sigmoidoscopy screening to prevent colorectal cancer: Baseline findings of a UK multicentre randomised trial. Lancet 2002;359:1291-300.

20. O'Leary BA, Olynyk JK, Neville AM, Platell CF. Cost-effectiveness of colorectal cancer screening: Comparison of community-based flexible sigmoidoscopy with fecal occult blood testing and colonoscopy. J Gastroenterol Hepatol 2004;19:38-47.

21. Frazier AL, Colditz GA, Fuchs CS, Kuntz KM. Cost-effectiveness of screening for colorectal cancer in the general population. JAMA 2000;284:1954-61.

22. Khandker RK, Dulski JD, Kilpatrick JB, Ellis RP, Mitchell JB, Baine WB. A decision model and cost-effectiveness analysis of colorectal cancer screening and surveillance guidelines for averagerisk adults. Int J Technol Assess Health Care 2000;16:799-810.

23. Spencer RJ, Ready RL. Utilization of nurse endoscopists for sigmoidoscopic examinations. Dis Colon Rectum 1977;20:94-6.

24. Rabeneck L, Paszat LF. Colorectal cancer screening in Canada: Why not consider nurse endoscopists? CMAJ 2003;169:206-7.

25. Maule WF. Screening for colorectal cancer by nurse endoscopists. N Engl J Med 1994;330:183-7.

26. Schoenfeld P, Piorkowski M, Allaire J, Ernst R, Holmes L. Flexible sigmoidoscopy by nurses: State of the art 1999. Gastroenterol Nurs 1999;22:254-61.

27. Palitz AM, Selby JV, Grossman S, et al. The Colon Cancer Prevention Program (CoCaP): Rationale, implementation, and preliminary results. HMO Pract 1997;11:5-12.

28. Wallace MB, Kemp JA, Meyer F, et al. Screening for colorectal cancer with flexible sigmoidoscopy by nonphysician endoscopists. Am J Med 1999;107:214-8. 
29. Schoenfeld P, Lipscomb S, Crook J, et al. Accuracy of polyp detection by gastroenterologists and nurse endoscopists during flexible sigmoidoscopy: A randomized trial. Gastroenterology 1999;117:312-8.

30. Schoenfeld PS, Cash B, Kita J, Piorkowski M, Cruess D, Ransohoff D. Effectiveness and patient satisfaction with screening flexible sigmoidoscopy performed by registered nurses. Gastrointest Endosc 1999;49:158-62.

31. Shapero TF, Alexander PE, Hoover J, Burgis E, Schabas R. Colorectal cancer screening: Video-reviewed flexible sigmoidoscopy by nurse endoscopists - a Canadian community-based perspective. Can J Gastroenterol 2001;15:441-5.

32. Smale S, Bjarnason I, Forgacs I, et al. Upper gastrointestinal endoscopy performed by nurses: Scope for the future? Gut 2003;52:1090-4.

33. Williams J, Russell I, Dural D, et al. What are the clinical outcome and cost-effectiveness of endoscopy undertaken by nurses when compared with doctors? A Multi-Institution Nurse Endoscopy Trial (MINuET). <http://www.cinahl.com/cexpress/hta/summ/ summ1040.pdf> (Version current at February 16, 2007).

34. NHS Modernisation Agency. Modernising endoscopy services: A practical guide to redesign. <http://www.nodelaysachiever.nhs.uk/ NR/rdonlyres/A19B505A-9470-4E30-92FD-B4C1C8C1C4BF/0/ RG0007Theendoscopyguide.pdf $>$ (Version current at February 16, 2007).

35. Royal College of Physicians, Royal College of Surgeons, Royal College of Radiologists, Royal College of General Practitioners. Guidelines for the training, appraisal and assessment of trainees in gastrointestinal endoscopy and for the assessment of units for registration and re-registration.

$<$ http://www.acpgbi.org.uk/documents/JAG_2004.pdf>

(Version current at February 16, 2007).

36. Guidelines for training non-specialists in screening flexible sigmoidoscopy. Gastrointest Endosc 2000;51:783-5.

37. Endoscopy by non-physicians: Guidelines for clinical application. From the ASGE. American Society for Gastrointestinal Endoscopy. Gastrointest Endosc 1999:49:826-8.

38. Cash BD, Schoenfeld PS, Ransohoff DF. Licensure, use, and training of paramedical personnel to perform screening flexible sigmoidoscopy. Gastrointest Endosc 1999;49:163-9.

39. Shapero TF, Hoover J, Paszat LF, et al. Colorectal cancer screening with nurse-performed flexible sigmoidoscopy: Results from a Canadian community-based program. Gastrointest Endosc 2006. (In press)

40. Ontario Task Force on Large Bowel Endoscopic Services. Increasing Colorectal Cancer Screening in Ontario through RN-Performed Flexible Sigmoidoscopy: Report and Recommendations of the Ontario Task Force on Large Bowel Endoscopic Services. Toronto: Cancer Care Ontario, 2005.

41. Duthie GS, Drew PJ, Hughes MA, et al. A UK training programme for nurse practitioner flexible sigmoidoscopy and a prospective evaluation of the practice of the first UK trained nurse flexible sigmoidoscopist. Gut 1998;43:711-4

42. Freeman ML. Training and competence in gastrointestinal endoscopy. Rev Gastroenterol Disord 2001;1:73-86. 


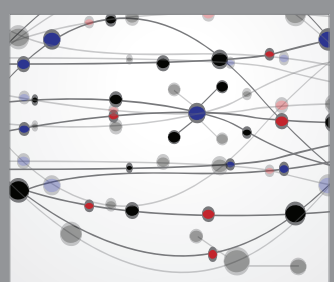

The Scientific World Journal
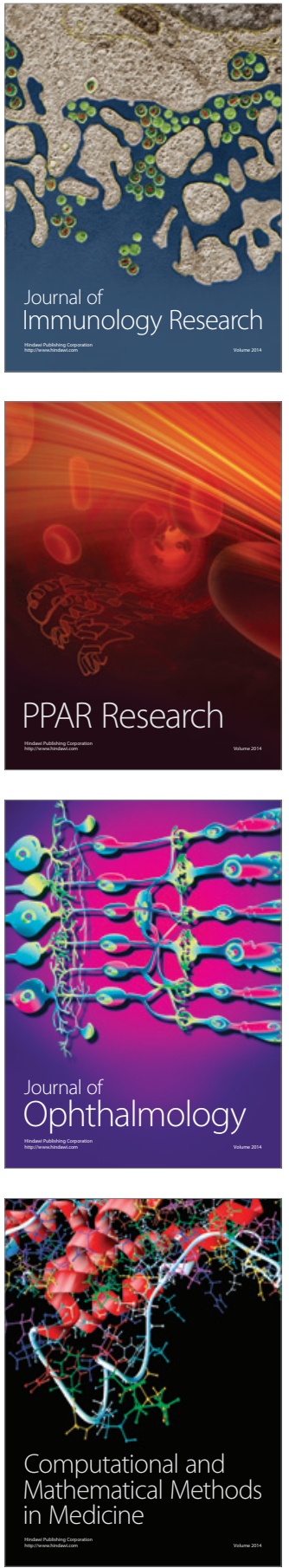

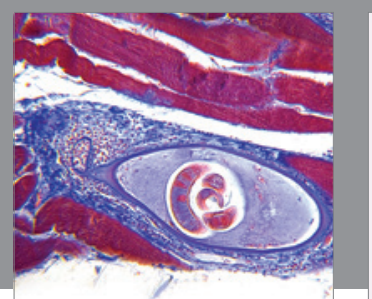

Gastroenterology Research and Practice

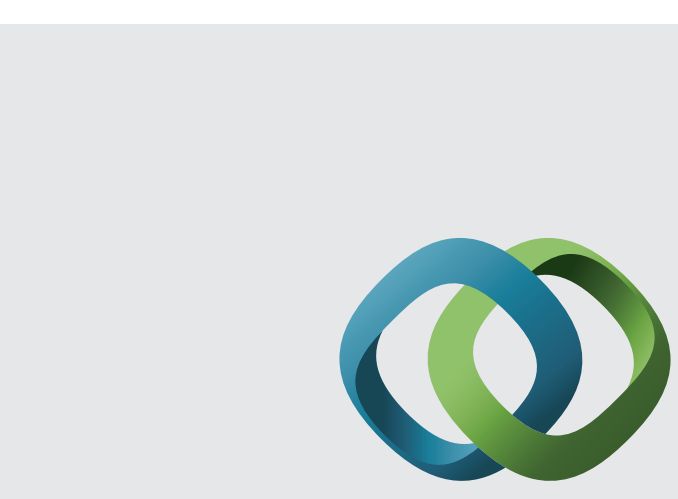

\section{Hindawi}

Submit your manuscripts at

http://www.hindawi.com
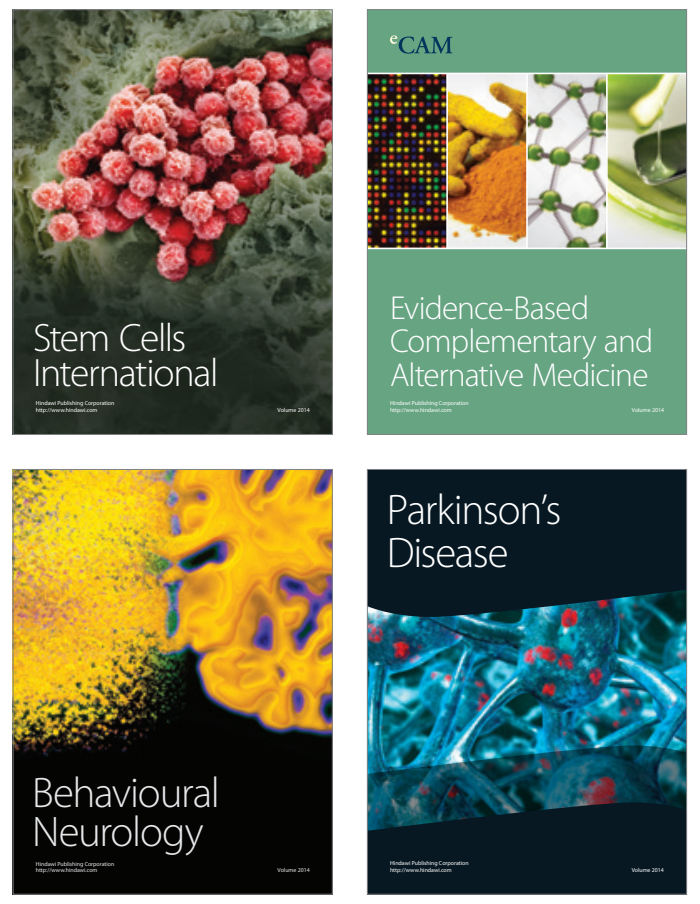
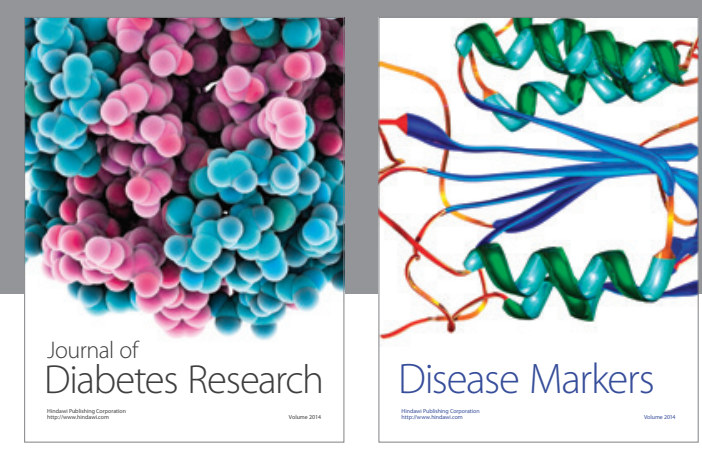

Disease Markers
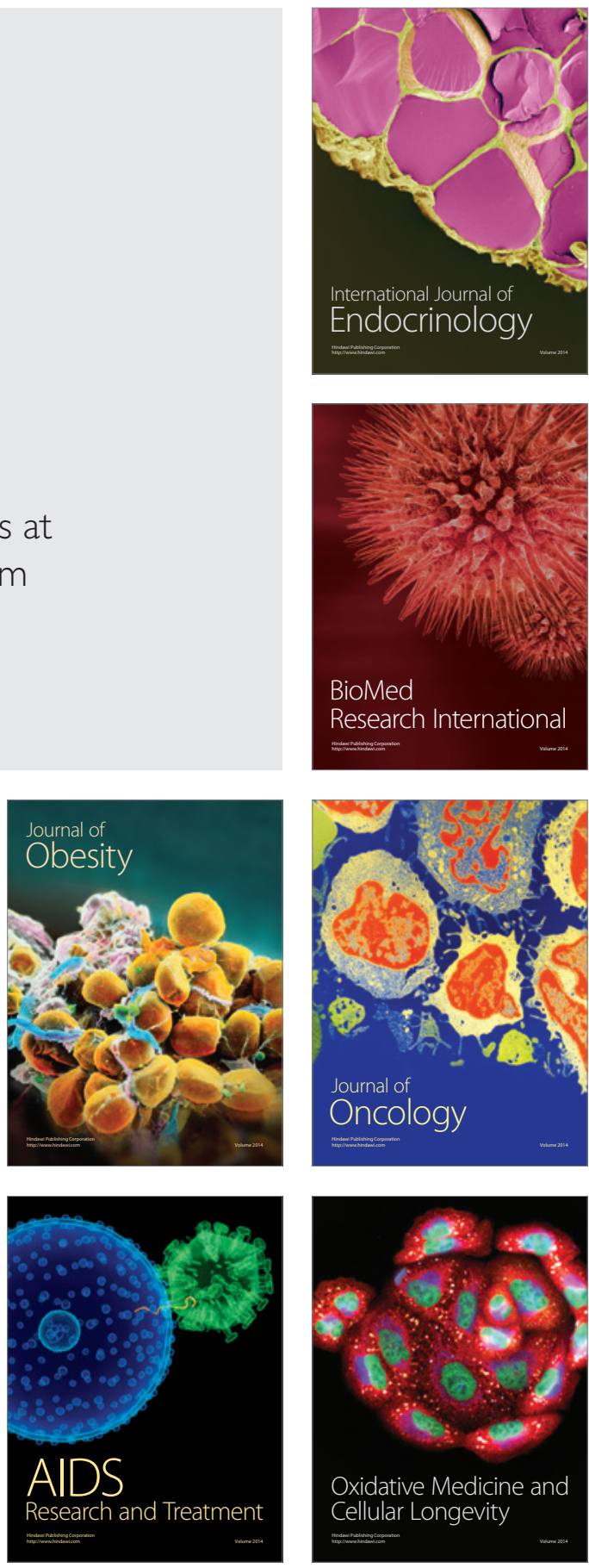